\title{
Viral-reactivated pneumonia during mechanical ventilation: is there need for antiviral treatment?
}

\author{
Alejandra López-Giraldo ${ }^{1,2,3}$, Salvador Sialer ${ }^{1,2,3}$, Mariano Esperatti $^{1,2,3}$ and Antoni Torres ${ }^{1,2,3}$ * \\ ${ }^{1}$ UVIR, Servei de Pneumologia, Hospital Clínic, Universitat de Barcelona, Barcelona, Spain \\ 2 IDIBAPS, Barcelona, Spain \\ ${ }^{3}$ CIBERES, Illes Baleares, Spain
}

\section{Edited by:}

Masakazu Ichinose, Wakayama

Medical University, Japan

Reviewed by:

Tobias Welte, Medizinische

Hochschule Hannover, Germany

Mutsuo Yamaya, Tohoku University

Graduate School of Medicine, Japan

*Correspondence:

Antoni Torres, Servei de Pneumologia, Hospital Clínic, Universitat de

Barcelona, Villarroel 170, 08036

Barcelona, Spain

e-mail: atorres@ub.edu
Respiratory viruses are not a common cause of ventilator-associated pneumonia (VAP). Herpesviridae [Herpes simplex virus (HSV) and cytomegalovirus (CMV)] are detected frequently in the lower respiratory tract of ventilated patients. HSV is detected between days 7 and 14 of invasive mechanical ventilation (IMV); presence of the virus does not necessarily imply pathogenicity, but the association with adverse clinical outcomes supports the hypothesis of a pathogenic role in a variable percentage of patients. Bronchopneumonitis associated with HSV should be considered in patients with prolonged IMV, reactivation with herpetic mucocutaneous lesions and those belonging to a risk population with burn injuries or acute lung injury. Reactivation of CMV is common in critically ill patients and usually occurs between days 14 and 21 in patients with defined risk factors. The potential pathogenic role of CMV seems clear in patients with acute lung injury and persistent respiratory failure in whom there is no isolation of bacterial agent as a cause of VAP. The best diagnostic test is not defined although lung biopsies should be considered in addition to the usual methods before starting specific treatment. The role of mimivirus is uncertain and is yet to be defined, but the serologic evidence of this new virus in the context of VAP appears to be associated with adverse clinical outcomes.

Keywords: viral pneumonia, ventilator-associated pneumonia, antiviral treatment

\section{INTRODUCTION}

Nosocomial pneumonia is the most commonly acquired infection in intensive care units (ICUs). Its Frequency is 10 cases/1000 admissions approximately, however, it may increase to 20 times that number in patients undergoing invasive mechanical ventilation (IMV; Celis et al., 1988; Torres et al., 1990; American Thoracic Society Documents, 2005). The overall incidence of ventilatorassociated pneumonia (VAP) may range between 15 and 20\% (Celis et al., 1988; Torres et al., 1990; Luna et al., 2003; Warren et al., 2003; Koulenti et al., 2009). This complication prolongs the length of hospital stay, increases healthcare costs and may increase mortality (Fagon et al., 1993; Kollef, 1993; Warren et al., 2003; Koulenti et al., 2009).

Classically, the etiology of this entity has been assumed to be bacterial, although in a significant percentage of patients with clinical suspected VAP, no bacteria can be identified.

In recent years, the introduction of highly sensitive techniques for detecting viruses in the respiratory tract, such as nucleic acid amplification by polymerase chain reaction (PCR), has significantly improved the diagnostic yield of infections such as community acquired pneumonia (CAP), increasing the isolation rate from less than $10 \%$ (using traditional techniques) to $35 \%$ when using PCR in CAP that requires hospital admission (Marcos et al., 2009).

Recently, new evidence has shown that viral isolation in the respiratory tract of immunocompetent patients undergoing IMV is higher than previously thought (Bruynseels et al., 2003; Ong et al.,
2004; Luyt et al., 2007). However, there are several limitations regarding determining the role of viruses in VAP:

- Difficulty in establishing a causal relationship between the viral isolate in the respiratory tract and pneumonia.

- Lack of an accessible gold standard for establishing the diagnosis.

- Lack of evidence regarding the efficacy of antiviral therapy in the context of suspected viral pneumonia during mechanical ventilation.

\section{INCIDENCE}

In critically ill immunocompetent patients undergoing IMV, two kind of virus may cause viral nosocomial pneumonia: Herpesviridae or the "classic" respiratory viruses (influenza A, parainfluenza, respiratory syncytial virus, rhinovirus, metapneumovirus, and adenovirus).

Although many clinical studies are focused on a particular aspect of the role of viruses in the critically ill patient, some studies have determined the frequency of viral respiratory tract involvement in patients with risk factors or suspected VAP.

Ideally, a study to address this issue should have an appropriate design (prospective cohort) and should systematically evaluate samples from the upper and lower respiratory tract and should include nucleic acid amplification (PCR). After an exhaustive review of the literature, only three studies meet most of these 


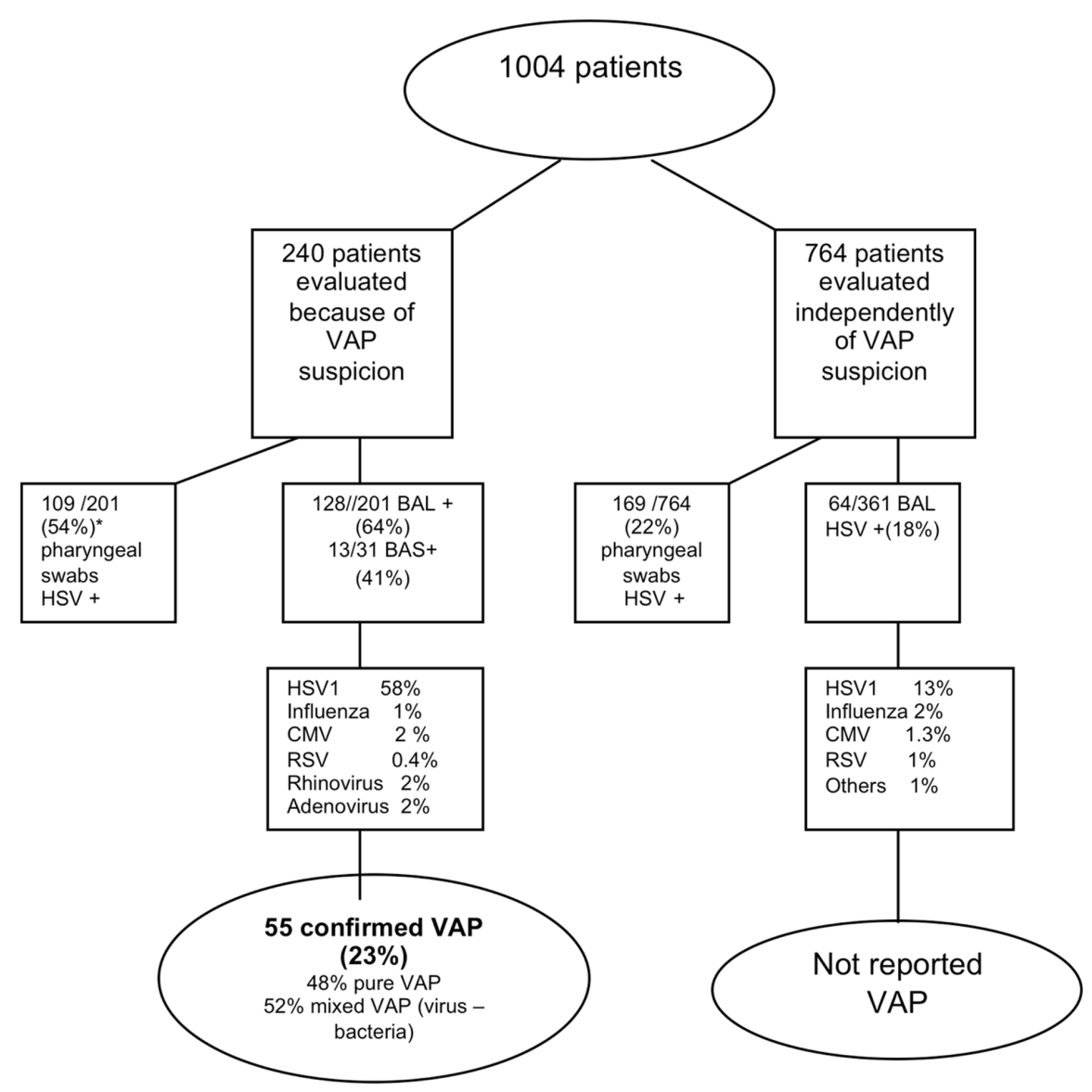

FIGURE 1 | Pooled analysis of studies that have evaluated the viral infection rate in the respiratory tract with more than one diagnostic method, including PCR and/or culture of virus in respiratory samples. * Two hundred one patients were evaluated with pharyngeal swab and BAL (Luyt et al., 2007). HSV-1, herpes simplex virus type 1; CMV, cytomegalovirus; RSV, respiratory syncytial virus; BAL, bronchoalveolar lavage; BAS, bronchoaspirate. requirements (Bruynseels et al., 2003; Daubin et al., 2005; Luyt et al., 2007). Figure 1 shows a pool analysis of these studies.

Although the presence of viruses in respiratory samples was not always accompanied by a definitive diagnosis of viral VAP and considering that not all the studies reported this final diagnosis, all of them reported a very low incidence of the "classic" respiratory viruses. Herpes simplex virus (HSV) and cytomegalovirus (CMV) were the most frequently isolated agents. For this reason, we will focus on the description of the most relevant aspects regarding respiratory infections associated with these viruses.

It should be clarified, that because viral pneumonia due to HSV and CMV during mechanical ventilation in the majority of cases is assumed to be a reactivation from a previous infection acquired outside the hospital, the term VAP, which implies nosocomial acquisition of the infection, will not be used, instead we will refer as viral reactivated pneumonia.

\section{HERPES SIMPLEX VIRUS}

Initial infection with the HSV usually occurs during childhood and is asymptomatic in most cases. A small percentage of patients may present with gingivostomatitis or pharyngitis.
Herpes simplex virus type 1 (HSV-1) may be isolated in the saliva of between 1 and $5 \%$ of the healthy population. Several factors such as tissue trauma, radiation therapy, heat exposure, and acute bacterial infections may cause reactivation of the infection from a latent state, causing lesions of the skin and mucosa (Simoons-Smit et al., 2006).

Lower respiratory tract infection with HSV-1 was initially considered as an entity exclusive of immunocompromised patients; however, in the past two decades different studies have indicated the potential role of HSV-1 in non-immunosuppressed patients who are critically ill.

\section{INCIDENCE AND RISK FACTORS}

Herpes simplex virus respiratory infection in nonimmunosuppressed critically ill patients was first reported in patients with ARDS in 1983 (Tuxen et al., 1982). The presence of HSV in the lower respiratory tract was previously thought to be exceptional. Four studies evaluated necropsy series of unselected patients between 1966 and 1982 and reported an incidence of 42 cases per 8535 patients $(0.5 \%)$ with a very high mortality and mainly affecting patients with underlying malignancies and 
extensive burns (Tuxen, 1994). It was therefore assumed that respiratory tract involvement of HSV was very unusual and associated with a poor prognosis.

Findings of a high incidence of HSV in patients with ARDS sparked interest in the hypothesis that HSV reactivation may play a role in an unfavorable clinical outcome in non-immunosuppressed critically ill patients. This was reflected in the increased number of publications reporting the frequency of HSV.

The overall incidence reported thereafter ranged between 5 and 64\% (Tuxen et al., 1982; Prellner et al., 1992; Schuller et al., 1993; Byers et al., 1996; Cook et al., 1998, 2003; Cherr et al., 2000; Bruynseels et al., 2003; Ong et al., 2004; Linssen et al., 2008; De Vos et al., 2009). The wide variability of the reported incidence of HSV was due to differences in study designs, study population, and the different use of diagnostic tests. Despite these differences, an especially susceptible population, and different risk factors such as extensive burns, ARDS, intubation, and prolonged IMV, positive serology for HSV-1 (IgG), appearance of herpetic mucocutaneous lesions, advanced age, high severity scores at admission, and use of systemic corticoid therapy during the ICU stay were identified.

It should be noted that, despite the widely varying incidence reported in the literature, the best quality study (in terms of design, adequate number of studied patients, use of highly sensitivity diagnostic tests, and consecutive evaluation of nonimmunosuppressed critically ill patients) showed a high incidence of HSV detection in the lower respiratory tract (64\%) and HSV bronchopneumonitis (21\%) among patients undergoing mechanical ventilation for more than 5 days (Luyt et al., 2007). In this study the presence of herpetic oral-labial lesions, positive pharyngeal swab, and macroscopic bronchial lesions were predictors for herpetic bronchopneumonitis.

Table 1 shows a detailed summary of studies evaluating lower respiratory tract infection caused by HSV-1 in critically ill patients since 1982.

\section{PATHOGENESIS}

Reactivation of the latent virus seems to be the initial mechanism of HSV respiratory infection: all patients with herpetic respiratory infection in the ICU have a previous HSV-positive serology and, usually, a pharyngeal swab positive for HSV, or oral-labial lesions preceding the lower tract infection (Bruynseels et al., 2003; De Vos et al., 2009).

Manipulation and traumatism of the airways predispose patients to viral reactivation in the oropharyngeal mucosa and upper airway, with subsequent micro-aspiration to further distal airways, thereby causing potential lung parenchyma involvement (Bruynseels et al., 2003; Simoons-Smit et al., 2006). Therefore, viral reactivation on the tracheobronchial mucosa explains why, in some cases, respiratory infection presents without any evidence of viruses in the oropharyngeal mucosa (Tuxen, 1994; Luyt et al., 2007).

Although hematogenous spread has been described, this mechanism seems to be limited to patients with a major degree of immunosuppression (Ramsey et al., 1982).

Typically, viral reactivation begins between day 3 and 5 of mechanical ventilation. This is followed by an exponential increase of the viral load in the inferior airways, which reaches a peak on day 12. Viral load at this point can reach up to $10^{8}$ copies $/ \mathrm{mL}$ as measured by PCR performed on tracheobronchial secretions (De Vos et al., 2009). This viral load corresponds to the viral concentration found in the vesicular lesions of the oral mucosa. This phase is followed by a slow decline of the viral load (Figure 2). This chronology appears relevant when considering the diagnosis of viral reactivated pneumonia on an individual basis.

It should be noted that a high viral load (assessed by viral culture) appears to correlate well with the diagnosis of bronchopneumonitis based on histologic examination (cytology of the bronchoalveolar lavage fluid and/or bronchial biopsies are assumed as the gold standard). A viral load of $8 \times 10^{4}$ copies $/ 10^{6}$ cells has a sensitivity and a specificity of 81 and $83 \%$ respectively for the diagnosis of herpetic bronchopneumonitis (Luyt et al., 2007).

In animal models, the instillation of HSV into the nostrils causes pneumonia and triggers a strong inflammatory response with extensive tissue damage secondary to induction of nitric oxide synthetase inducible enzyme on the lung parenchyma. Inhibition of this enzyme improves tissue damage, pulmonary compliance, and survival. Interestingly, these effects are independent of the viral load, suggesting a mechanism of inflammatory response amplification rather than direct viral pathogenicity (Adler et al., 1997).

It should be noted that although viral reactivation is the main mechanism of pathogenesis of HSV pneumonia during mechanical ventilation, there has been reported several cases of HSV clusters due to nosocomial transmission in the ICU (Engelmann et al., 2007).

\section{CLINICAL OUTCOMES}

The detection of HSV in the lower respiratory tract does not necessarily mean lung infection and, on an individual basis, it is unclear whether it represents viral contamination of the lower respiratory tract from the mouth and/or throat, local tracheobronchial viral excretion or HSV bronchopneumonitis (Simoons-Smit et al., 2006). For these reasons, the exact role of HSV remains to be clarified: is it just a marker of disease severity or a real pathogen with its own morbidity and mortality?

The analysis is even more complicated when the association of virus and bacteria in "viral" VAP ( $52 \%$ of cases) is taken into consideration (Bruynseels et al., 2003; Luyt et al., 2007).

Several studies have found a higher number of days on mechanical ventilation and longer stays in the ICU and/or hospital in patients infected with HSV (Tuxen et al., 1982; Bruynseels et al., 2003; Daubin et al., 2005; De Vos et al., 2009). Interestingly, these were prospective studies that evaluated a large number of patients and failed to show an increase in mortality.

The only prospective study that is often cited as an example of increased mortality in the group of $\mathrm{HSV}+$ patients did not reach statistical significance when adjusted for severity, assessed by APACHE II, which indicates that the results did not appear to be consistent (Ong et al., 2004).

The studies that found increased mortality on infected patients with HSV were retrospective (Cook et al., 1998; Bruynseels et al., 2003) or prospective with a very small sample size and limited to populations with ARDS (Tuxen et al., 1982). 

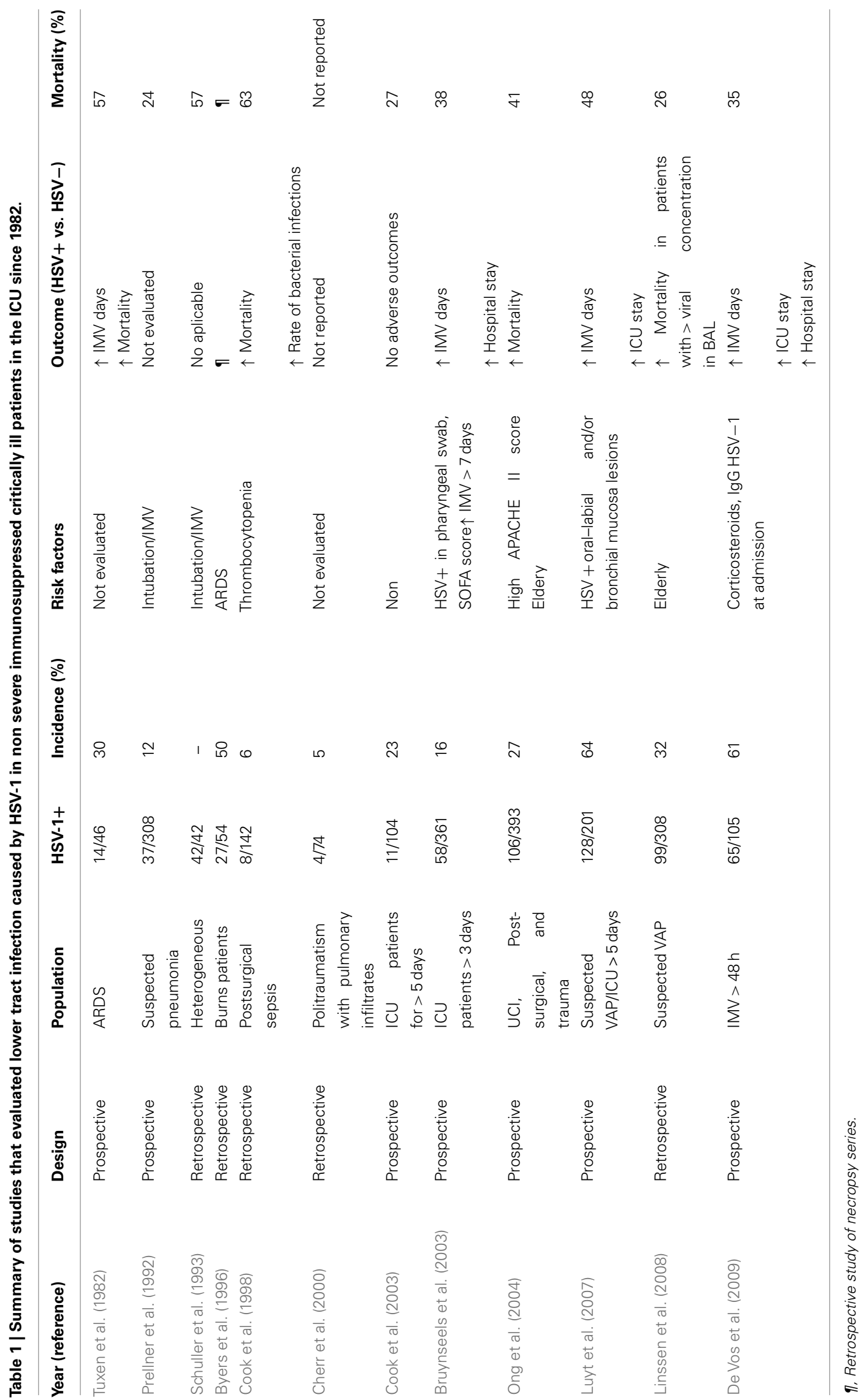


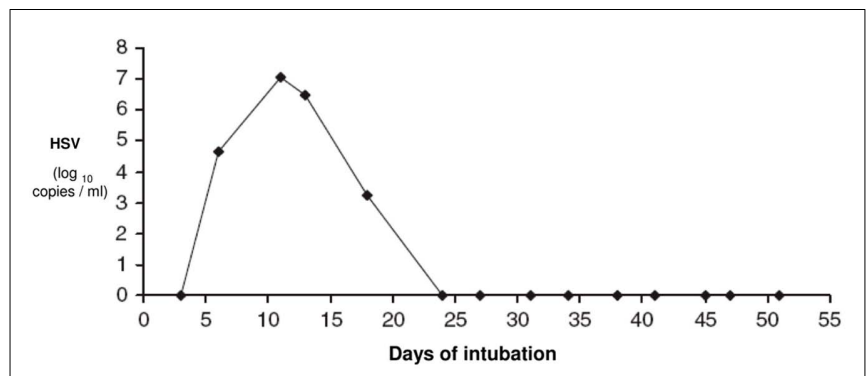

FIGURE 2 | Kinetics of HSV reactivation in patients undergoing IMV evaluated with PCR on bronchoaspirate specime.

In consequence, the question of the effects of infection on mortality remains to be clarified.

\section{TREATMENT}

Despite the high incidence and association with adverse clinical outcomes, there are no randomized control trials that make possible to provide definitive recommendations regarding intervention in these patients.

In all the studies mentioned, treatment was prescribed by the clinicians and analysis of clinical outcomes under uncontrolled conditions are not available. The only intervention study was a small randomized trial that evaluated the efficacy and safety of acyclovir for preventing reactivation of HSV in patients with ARDS (Tuxen et al., 1987).

Although acyclovir was effective in preventing viral reactivation in the respiratory tract (absolute risk reduction of 65\%), there was no difference in severity of respiratory failure, duration of mechanical ventilations, and mortality between the control and intervention arms.

Given the particular characteristics of this phenomenon (high incidence, association with unfavorable clinical outcomes, and potential therapeutic interventions), the need for randomized clinical trials that might clarify this matter is imperative.

\section{CYTOMEGALOVIRUS}

Most healthy immunocompetent adults have been infected with CMV, a fact that is evidenced by the presence of specific immunoglobulin (Ig) $G$ for this virus (Limaye et al., 2008). In most cases, the infection remains latent without causing disease. Reactivation and CMV disease has traditionally been described in populations with marked alterations in cellular immunity (Anderson, 1991). However, in the past two decades there has been increasing evidence to show that reactivation of CMV is a common finding in the immunocompetent critically ill patients (Kalil and Florescu, 2009). The frequency varies, according to the diagnostic methods used, from $12 \%$ when cultures are used to $33 \%$ when PCR is used (Limaye et al., 2008).

Viral reactivation begins between days 14 and 21 of the ICU stay. Risk factors for reactivation are prolonged ICU stays, higher severity scores on admission, and severe sepsis. In this group the incidence may reach up to $36 \%$. Although a clear cause and effect has not been found, reactivation is associated with increased mortality and longer hospital stay (Limaye et al., 2008; Kalil and Florescu, 2009).
Viral reactivation in humans can begin in the lung parenchyma (Papazian et al., 1996; Cook et al., 1998, 2003). In animal models with latent $\mathrm{CMV}$, sepsis may produce pulmonary reactivation of the viral infection; this reactivation is associated with a persistent increase of cytokine-mediated inflammatory response in the lung and both findings (reactivation and persistent inflammation) do not occur in the presence of prior ganciclovir treatment (Cook et al., 2006).

Thus, to the epidemiological evidence of the association of CMV-unfavorable clinical outcomes is added the biological evidence of potential pathogenicity in the lungs.

In 1996, Papazian et al. (1996) published the first study that showed a high incidence of CMV reactivated pneumonia during mechanical ventilation. The authors studied 85 patients with ARDS, prolonged mechanical ventilation and suspected VAP with negative cultures for bacteria in respiratory specimens (25 open lung biopsies and 60 post mortem biopsies). Conclusive histopathological findings of CMV pneumonia were found in 25 patients (only three cases also showed evidence of bacterial pneumonia).

The same authors studied the diagnostic value of open lung biopsies on patients with acute lung injury, suspected VAP and negative cultures of respiratory specimens, evaluating their utility for potential changes to therapeutic interventions. In a sample of 100 patients, evidence of CMV infection was found in 30 subjects (three patients had HSV findings), four cases also showed evidence of ARDS in a fibroproliferative phase. Together with the diagnosis of pulmonary fibrosis, CMV pneumonia was the most frequent finding that conditioned changes in medical treatment (Papazian et al., 2007).

The value of the different diagnostic techniques is not clear; thus, in the first study mentioned, the BAL culture had a sensitivity and a specificity of 53 and $92 \%$ respectively (Papazian et al., 1996). In another study by the same authors, diagnosis was made based on histopathologic findings after negative cultures and negative pp. 65 antigenemia (Papazian et al., 2007). The only study that evaluated PCR assay in BAL in an unselected sample of patients with suspected VAP found 13\% of positive samples without cytoplasmic inclusions and no histological evaluation was performed; it was therefore not possible to reach a definitive diagnosis (Luyt et al., 2007).

Consequently, the diagnosis CMV pneumonia during mechanical ventilation may be more common than thought, but there are difficulties and issues that still need to be clarified regarding the appropriate diagnostic tests. The above studies suggest a low sensitivity of standard diagnostic tests. However, in the populations studied, CMV appears to have a clear pathogenic role, as evidenced by the extensive presence of pneumonitis and of cytoplasmic inclusions in biopsy specimens (Papazian et al., 1996, 2007).

Individual management of each patient, is further complicated when considering the risk and benefits of treatment with ganciclovir, which has potential serious adverse effects.

For these reasons, randomized clinical trials are needed to clarify the role of antiviral treatment in patients with CMV reactivation.

Similarly, it is difficult to make a final recommendation regarding the overall approach to individual patients with suspected 
CMV pneumonia during mechanical ventilation. It may be recommendable to suspect this entity in patients with the before mentioned risk factors and persistent pulmonary infiltrates with clinical deterioration and no evidence of bacterial infection. If the patient also shows evidence of viral reactivation (preferably assessed by PCR), initiation of antiviral therapy should be considered. Lung biopsy appears to play an important role in this group of patients because it can demonstrate CMV pneumonia even when respiratory specimens are negative.

\section{MIMIVIRUS}

Acanthamoeba polyphaga (mimivirus) is a double-stranded DNA virus with the largest viral genome yet described (Raoult et al., 2004). Although it was thought to be a potential causative agent of pneumonia, it's role in this entity has not been categorically defined.

The finding of this microorganism was described in 1992 as part of a suspected outbreak of Legionella pneumonia. Initially categorized as a bacteria, it was finally reclassified as a virus in 2003. Subsequently, serological evidence of mimivirus was reported in between 7 and $9 \%$ of patients with community acquired and nosocomial pneumonia (La Scola et al., 2005; Berger et al., 2006).

The potential role of this virus has been questioned in a study that evaluated cohorts with pneumonia using different serologies; results were negative in all cases. The nosocomial pneumonia cohort included 71 samples of elderly patients from health care centers; it is not known if any of them received IMV (Dare et al., 2008).

However, only one study has systematically evaluated ventilated patients with suspected VAP (Vincent et al., 2009). Of 300 patients with suspected VAP, 59 had positive serology for mimivirus (19.6\%), 64\% of those had positive BAL for bacteria. A comparison of mimivirus-seropositive patients with a seronegative group matched for age, diagnostic category, and severity showed that the seropositive group experienced increase duration of MV and ICU stay; no differences in mortality were found. It should be noted that the overall effectiveness of matching was of $95 \%$ and other relevant variables such as adequate

\section{REFERENCES}

Adler, H., Beland, J. L., Del-Pan, N. C., Kobzik, L., Brewer, J. P., Martin, T. R., and Rimm, I. J. (1997). Suppression of herpes simplex virus type 1 (HSV1)-induced pneumonia in mice by inhibition of inducible nitric oxide synthase (iNOS, NOS2). J. Exp. Med. 185, 1533-1540.

American Thoracic Society Documents. (2005) Guidelines for the management of adults with hospitalacquired pneumonia, ventilatorassociated pneumonia, and healthcare associated pneumonia. Am. J. Respir. Crit. Care Med. 17, 388-416.

Anderson, L. J. (1991). Major trends in nosocomial viral infections. Am. J. Med. 91, 107S-111S.

Berger, P., Papazian, L., Drancourt, M., La Scola, B., Auffray, J. P., and
Raoult, D. (2006). Ameba-associated microorganisms and diagnosis of nosocomial pneumonia. Emerg. Infect. Dis. 12, 248-255.

Bruynseels, P., Jorens, P. G., Demey, H. E., Goossens, H., Pattyn, S. R., Elseviers, M. M., Weyler, J., Bossaert, L. L., Mentens, Y., and Ieven, M. (2003). Herpes simplex virus in the respiratory tract of critical care patients: a prospective study. Lancet 362, 1536-1541.

Byers, R. J., Hasleton, P. S., Quigley, A., Dennett, C., Klapper, P. E., Cleator, G. M., and Faragher, E. B. (1996). Pulmonary herpes simplex in burns patients. Eur. Respir. J. 9, 2313-2317.

Celis, R., Torres, A., Gatell, J. M., Almela, M., Rodríguez-Roisin, R., and Agustí-Vidal, A. (1988). Nosocomial pneumonia: a

antibacterial therapy and the bacteremia rate were similar in both groups.

Thus, although no definitive recommendations can be made regarding the screening of this microbiological agent, there is ongoing cumulative evidence of the potential role of this new virus in VAP.

\section{CONCLUSION}

Respiratory viruses are not a common cause of VAP. Herpesviridae (HSV and CMV) are detected frequently in the lower respiratory tract of ventilated patients. HSV is detected between days 7 and 14 of IMV; presence of the virus does not necessarily imply pathogenicity, but the association with adverse clinical outcomes supports the hypothesis of a pathogenic role in a variable percentage of patients. Bronchopneumonitis associated with HSV should be considered in patients with prolonged IMV, reactivation with herpetic mucocutaneous lesions and those belonging to a risk population with burn injuries or acute lung injury.

Reactivation of CMV is common in critically ill patients and usually occurs between days 14 and 21 in patients with defined risk factors. The potential pathogenic role of CMV seems clear in patients with acute lung injury and persistent respiratory failure in whom there is no isolation of bacterial agent as a cause of VAP. The best diagnostic test is not defined although lung biopsies should be considered in addition to the usual methods before starting specific treatment.

Due to the lack of randomized clinical trials, it is not possible to make a definitive recommendation regarding the antiviral treatment for suspected HSV or CMV reactivation pneumonia during mechanical ventilation. The decision to start antiviral treatment should be made on an individual basis, taking into consideration the risk factors mentioned above, a correct interpretation of diagnostic methods and the hole clinical picture of the patient. There is an imperative need for randomized clinical trials to address this aspect.

The role of mimivirus is uncertain and still needs to be defined, but the serologic evidence of this new virus in the context of VAP appears to be associated with adverse clinical outcomes.

multivariate analysis of risk factors and prognosis. Chest 93, 318-324.

Cherr, G. S., Meredith, J. W., and Chang, M. (2000). Herpes simplex pneumonia in trauma patients. J. Trauma 49, 547-549.

Cook, C. H., Martin, L. C., Yenchar, J. K., Lahm, M. C., McGuinness, B., Davies, E. A., and Ferguson, R. M. (2003). Occult herpes family viral infections are endemic in critically ill surgical patients. Crit. Care Med. 31, 1923-1929.

Cook, C. H., Yenchar, J. K., Kraner, T. O., Davies, E. A., and Ferguson, R. M. (1998). Occult herpes family viruses may increase mortality in critically Ill surgical patients. Am. J. Surg. 176, 357-360.

Cook, C. H., Zhang, Y., Sedmak, D. D., Martin, L. C., Jewell, S., and Ferguson, R. M. (2006) Pulmonary cytomegalovirus reactivation causes pathology in immunocompetent mice. Crit. Care Med. 34, 842-849.

Dare, R. K., Chittaganpitch, M., and Erdman, D. D. (2008). Screening pneumonia patients for mimivirus. Emerg. Infect. Dis. 14, 465-467.

Daubin, C., Vincent, S., and Vabret, A. (2005) Nosocomial viral ventilatorassociated pneumonia in the intensive care unit: a prospective cohort study. Intensive Care Med. 31, 1116-1122.

De Vos, N., Van Hoovels, L., and Vankeerberghen, A. (2009). Monitoring of herpes simplex virus in the lower respiratory tract of critically ill patients using real-time PCR: a prospective study. Clin. Microbiol. Infect. 15, 358-363. 
Engelmann, I., Gottlieb, J., Meier, A., Sohr, D., Ruhparwar, A., HenkeGendo, C., Gastmeier, P., Welte, T., Schulz, T. F., and Mattner, F. (2007). Clinical relevance of and risk factors for HSV-related tracheobronchitis or pneumonia: results of an outbreak investigation. Crit. Care 11, R119.

Fagon, J. Y., Chastre, J., Hance, A. J., Montravers, P., Novara, A., and Gibert, C. (1993). Nosocomial pneumonia in ventilated patients: a cohort study evaluating attributable mortality and hospital stay. Am. J. Med. 94, 281-288.

Kalil, A. C., and Florescu, D. F. (2009). Prevalence and mortality associated with cytomegalovirus infection in nonimmunosuppressed patients in the intensive care unit. Crit. Care Med. 37, 2350-2358.

Kollef, M. H. (1993). Ventilatorassociated pneumonia. A multivariate analysis. JAMA 270, 1965-1970.

Koulenti, D., Lisboa, T., Brun-Buisson, C., Krueger, W., Macor, A., SoleViolan, J., Diaz, E., Topeli, A., DeWaele, J., Carneiro, A., MartinLoeches, I., Armaganidis, A., Rello, J., and EU-VAP/CAP Study Group. (2009). Spectrum of practice in the diagnosis of nosocomial pneumonia in patients requiring mechanical ventilation in European intensive care units. Crit. Care Med. 37, 2360-2368.

La Scola, B., Marrie, T. J., Auffray, J. P., and Raoult, D. (2005). Mimivirus in pneumonia patients. Emerg. Infect. Dis. 11, 449-452.

Limaye, A. P., Kirby, K. A., Rubenfeld, G. D., Leisenring, W. M., Bulger, E. M., Neff, M. J., Gibran, N. S., Huang, M. L., Santo, Hayes, T. K., Corey, L., and Boeckh, M. (2008). Cytomegalovirus reactivation in critically ill immunocompetent patients. JAMA 300, 413-422.

Linssen, C. F., Jacobs, J. A., Stelma, F. F., van Mook, W. N., Terporten, P., Vink, C., Drent, M., Bruggeman, C. A., and
Smismans, A. (2008) Herpes simplex virus load in bronchoalveolar lavage fluid is related to poor outcome in critically ill patients. Intensive Care Med. 34, 2202-2209.

Luna, C. M., Blanzaco, D., Niederman, M. S., Matarucco, W., Baredes, N. C. Desmery, P., Palizas, F., Menga, G., Rios, F., and Apezteguia, C. (2003). Resolution of ventilator-associated pneumonia: prospective evaluation of the clinical pulmonary infection score as an early clinical predictor of outcome. Crit. Care Med. 31, 676-682.

Luyt, C. E., Combes, A., Deback, C., Aubriot-Lorton, M. H., Nieszkowska, A., Trouillet, J. L., Capron, F., Agut, H., Gibert, C., and Chastre, J. (2007). Herpes simplex virus lung infection in patients undergoing prolonged mechanical ventilation. Am. J. Respir. Crit. Care Med. 175, 935-942.

Marcos, M. A., Esperatti, M., and Torres, A. (2009). Viral pneumonia. Curr. Opin. Infect. Dis. 22, 143-147.

Ong, G. M., Lowry, K., Mahajan, S., Wyatt, D. E., Simpson, C., O’Neill, H. J., McCaughey, C., and Coyle, P. V. (2004). Herpes simplex type 1 shedding is associated with reduced hospital survival in patients receiving assisted ventilation in a tertiary referral intensive care unit. J. Med. Virol. 72, 121-125.

Papazian, L., Doddoli, C., Chetaille, B., Gernez, Y., Thirion, X., Roch, A., Donati, Y., Bonnety, M., Zandotti, C., and Thomas, P. (2007). A contributive result of open-lung biopsy improves survival in acute respiratory distress syndrome patients. Crit. Care Med. 35, 755-762.

Papazian, L., Fraisse, A., Garbe, L., Zandotti, C., Thomas, P., Saux, P., Pierrin, G., and Gouin, F. (1996). Cytomegalovirus. An unexpected cause of ventilator-associated pneumonia. Anesthesiology 84, 280-287.

Prellner, T., Flamholc, L., Haidl, S., Lindholm, K., and Widell, A. (1992).
Herpes simplex virus - the most frequently isolated pathogen in the lungs of patients with severe respiratory distress. Scand. J. Infect. Dis. 24, 283-292.

Ramsey, P. G., Fife, K. H., Hackman, R. C., Meyers, J. D., and Corey, L. (1982) Herpes simplex virus pneumonia: clinical, virologic, and pathologic features in 20 patients. Ann. Intern. Med. 97, 813-820.

Raoult, D., Audic, S., Robert, C. Abergel, C., Renesto, P., Ogata, H., La Scola, B., Suzan, M., Claverie, J. M. (2004). The 1.2-megabase genome sequence of mimivirus. Science 306, 1344-1350.

Schuller, D., Spessert, C., Fraser, V. J. and Goodenberger, D. M. (1993). Herpes simplex virus from respiratory tract secretions: epidemiology, clinical characteristics, and outcome in immunocompromised and nonimmunocompromised hosts. Am. J. Med. 94, 29-33.

Simoons-Smit, A. M., Kraan, E. M. Beishuizen, A., Strack van Schijndel, R. J., and Vandenbroucke-Grauls, C. M. (2006). Herpes simplex virus type 1 and respiratory disease in critically-ill patients: real pathogen or innocent bystander? Clin. Microbiol. Infect. 12, 1050-1019.

Torres, A., Aznar, R., Gatell, J. M. Jiménez, P., González, J., Ferrer, A., Celis, R., and Rodriguez-Roisin, R. (1990). Incidence, risk, and prognosis factors of pneumonia in mechanically ventilated patients. Am. Rev Respir. Dis. 142, 523-528.

Tuxen, D. V. (1994). Prevention of lower respiratory herpes simplex virus infection with acyclovir in patients with adult respiratory distress syndrome. Chest. 106, 28S-33S.

Tuxen, D. V., Cade, J. F., McDonald, M. I., Buchanan, M. R., Clark, R. J., and Pain, M. C. (1982). Herpes simplex virus from the lower respiratory tract in adult respiratory distress syndrome. Am. Rev. Respir. Dis. $126,416-419$
Tuxen, D. V., Wilson, J. W., and Cade, J. F. (1987). Prevention of lower respiratory herpes simplex virus infection with acyclovir in patients with the adult respiratory distress syndrome. Am. Rev. Respir. Dis. 136, 402-405.

Vincent, A., La Scola, B., Forel, J. M., Pauly, V., Raoult, D., and Papazian, L. (2009) Clinical significance of a positive serology for mimivirus in patients presenting a suspicion of ventilator-associated pneumonia. Crit. Care Med. 37, 111-118.

Warren, D. K., Shukla, S. J., Olsen, M. A., Kollef, M. H., Hollenbeak, C. S., Cox, M. J., Cohen, M. M., and Fraser, V. J. (2003). Outcome and attributable cost of ventilatorassociated pneumonia among intensive care unit patients in a suburban medical center. Crit. Care Med. 31, 1312-1317.

Conflict of Interest Statement: The authors declare that the research was conducted in the absence of any commercial or financial relationships that could be construed as a potential conflict of interest.

Received: 14 July 2011; paper pending published: 26 July 2011; accepted: 11 October 2011; published online: 08 November 2011.

Citation: López-Giraldo A, Sialer S, Esperatti $M$ and Torres A (2011) Viralreactivated pneumonia during mechanical ventilation: is there need for antiviral treatment? Front. Pharmacol. 2:66. doi: 10.3389/fphar.2011.00066

This article was submitted to Frontiers in Respiratory Pharmacology, a specialty of Frontiers in Pharmacology.

Copyright (c) 2011 López-Giraldo, Sialer, Esperatti and Torres. This is an openaccess article subject to a non-exclusive license between the authors and Frontiers Media SA, which permits use, distribution and reproduction in other forums, provided the original authors and source are credited and other Frontiers conditions are complied with. 